\title{
The functional EGF+61 polymorphism and nonsyndromic oral clefts susceptibility in a Brazilian population
}

\author{
Priscila FALAGAN-LOTSCH ${ }^{1,6}$, Talíria Silva LOPES ${ }^{1,2}$, Erika Calvano KÜCHLER ${ }^{1,3}$, Patrícia Nivoloni TANNURE ${ }^{1}$, \\ Marcelo de Castro COSTA ${ }^{4}$, Lidia Maria da Fonte de AMORIM ${ }^{5}$, José Mauro GRANJEIRO ${ }^{6}$
}

\author{
1- Cell Therapy Center, Unit of Clinical Research, University Hospital Antonio Pedro, Fluminense Federal University, Niterói, RJ, Brazil. \\ 2- Post-graduation Program in Science (Biotechnology), Institute of Biology, Fluminense Federal University, Niterói, RJ, Brazil. \\ 3- Department of Pediatrics, University of São Paulo, Ribeirão Preto, SP, Brazil. \\ 4- Department of Pediatric Dentistry and Orthodontics, Federal University of Rio de Janeiro, Rio de Janeiro, RJ, Brazil. \\ 5- Department of Cell and Molecular Biology, Institute of Biology, Fluminense Federal University, Niterói, RJ, Brazil. \\ 6- Laboratory of Biotechnology, National Institute of Metrology, Quality and Technology (INMETRO), Duque de Caxias, Rio de Janeiro, RJ, Brazil.
}

Corresponding address: Priscila Falagan Lotsch - INMETRO - Av. Nossa Senhora das Graças, 50, Vila Operária - Xerém, Duque de Caxias - RJ - Brazil 25250-020 - Phone: +55 2121459834 - Fax: +55 2126799837 - e-mail: pflotsch@inmetro.gov.br - prifalagan@gmail.com

Submitted: December 17, 2014 - Modification: March 17, 2015 - Accepted: March 19, 2015

\section{ABSTRACT}

$\mathrm{N}$ onsyndromic oral clefts are considered a problem of public health in Brazil, presenting a multifactorial etiology that involves genetic and environmental components, such as maternal alcohol consumption. Several candidate genes have been investigated to identify some association with nonsyndromic clefts risk. The epidermal growth factor (EGF) gene is implicated in the normal craniofacial development and its functional +61 A $>$ G polymorphism has been related to cancer susceptibility. It has been suggested that cancer and oral clefts may share the same molecular pathways. Objective: Our goal was to evaluate the association between the EGF+61 A>G polymorphism and nonsyndromic oral clefts susceptibility. Material and Methods: The case-control study included 218 cleft cases and 253 controls from Brazil. The control group was comprised of individuals without congenital malformations, dental anomalies and family history of clefts. The cleft phenotypes and subphenotypes were determined based on clinical examination. Genomic DNA was extracted from oral mucosa cells obtained by mouthwash. The EGF+61 A>G polymorphism genotype was determined by polymerase chain reaction-restriction fragment length polymorphism. Results: We noticed the association between maternal alcohol consumption during pregnancy and cleft occurrence. The A allele and AA genotype were over-represented in cleft cases compared with control group when we considered the bilateral cleft lip with or without cleft palate $(C L \pm P)$ cases, cleft cases with tooth agenesis and cleft cases presenting family history of cleft, but the differences were not statistically significant. Contradictorily, the G allele was higher in cleft palate only (CP) cases than in control group, showing a borderline $\mathrm{p}$ value. Comparing the different cleft phenotypes, we observed statistical differences between $C P$ and $C L \pm P$ cases. Our data suggest the EGF+61 A>G polymorphism was not related with nonsyndromic oral clefts susceptibility in a Brazilian population, but supported the different genetic background between CL $\pm P$ and CP. Moreover, we confirmed the potential effect of maternal alcohol intake on cleft risk in our population.

Keywords: Nonsyndromic oral clefts. Cleft subphenotypes. EGF. Polymorphism.

\section{INTRODUCTION}

Congenital malformations comprise $2-3 \%$ of all human live births, being one of the major causes of childhood mortality in developed countries. The oral clefts are the most common craniofacial anomaly in humans, affecting approximately one in every 500 to 1,000 live births worldwide ${ }^{25}$. In Brazil, the 
estimated prevalence is 0.36 in 1,000 live births and the Southeast region shows a prevalence of 0.34 per 1,000 live births ${ }^{27}$.

Besides the facial abnormalities, individuals affected present several complications such as speech, hearing and dental disorders. Associated defects, especially involving cardiovascular, central nervous and musculoskeletal systems, are commonly seen, as well as the psychosocial effects from the malformation experienced lifelong ${ }^{18}$.

The oral clefts arise from failure of normal craniofacial developmental processes that require the coordination of a complex series of events involving cell growth, migration, differentiation, and apoptosis ${ }^{18}$. Nonsyndromic oral clefts are observed in approximately $70 \%$ of the cases, occurring as an isolated condition unassociated with any other recognizable anomalies ${ }^{28}$. In Brazil, this defect is considered a problem of public health, since about 4,000 new cases are expected every year ${ }^{4}$.

The nonsyndromic oral clefts are composed of two separate entities: cleft lip with or without cleft palate $(C L \pm P)$ and cleft palate only $(C P)$. Moreover, evidences show that $C L \pm P$ and $C P$ are developmentally distinct entities. Despite the efforts that have been made to elucidate the oral clefts etiology, the understanding about nonsyndromic variants still remains unknown ${ }^{11}$. In general, nonsyndromic oral clefts are considered being from a multifactorial origin, involving mainly environmental and genetic components ${ }^{25}$. Regarding the environmental components, mother's habits such as alcohol intake and smoking during pregnancy are pointed out as risk factors to oral clefts ${ }^{17}$. On the other hand, recent advances into both genetics and molecular biology fields have been decisive for promoting an increase in the knowledge about the basis of craniofacial development, bringing a number of genes associated with mammals cleft development.

Several candidate genes have been investigated to identify some association with nonsyndromic clefts, including growth factors such as EGF5,24. A single gene on chromosome $4 q 25-q 27$ encodes the epidermal growth factor (EGF). EGF has an effect on the differentiation and is a potent mitogenic factor for a variety of cultured cells of both ectodermal and mesodermal origin. The protein EGF binds to its receptor (EGFR), leading to a signaling transduction cascade activation that will ultimately influence cell proliferation, inhibition of apoptosis and differentiation. EGF is expressed in several developing organs and it has been implicated to play roles in odontogenesis ${ }^{15}$, mandibular morphogenesis ${ }^{30}$, embryogenesis and also normal palate development ${ }^{13}$.

It has been suggested that EGF contributes to a successful fusion of the facial prominences and outgrowth of the primary palate ${ }^{13}$. Also, changes in EGF expression affecting the proliferation of epithelial cells have been related to cleft palate development ${ }^{1}$.

Genetic variations in the EGF may lead to an alteration in the protein production and activity, affecting an individual susceptibility to many types of conditions, including oral clefts. A single nucleotide polymorphism (SNP) in the $5^{\prime}$ untranslated region of the gene (rs 4444903; g.109912954A>G - HGVS nomenclature) was identified and characterized by an $A$ to $G$ transversion found $61 b p$ downstream of the EGF transcription start site $(E G F+61 A>G)$. In vitro analysis suggested changes in EGF expression levels caused by this base substitution ${ }^{29}$. The functional EGF+61 A>G polymorphism is the most widely studied variation in the EGF gene and it has been associated with increased risk of many types of cancer, including melanoma ${ }^{29}$, glioma ${ }^{12}$, hepatocellular carcinoma ${ }^{21}$, among others. Interestingly, some reports have observed the association between congenital malformation and cancer ${ }^{7,8}$, suggesting that the individuals born with oral clefts have a higher susceptibility for cancer, raising the hypothesis that, in some instances, these two conditions share common molecular pathways.

Afterwards, considering the potential implication of EGF gene polymorphism affecting the normal craniofacial development and its relation with cancer susceptibility, we assessed the association between the functional EGF+61 $A>G$ variation and nonsyndromic oral clefts risk in a Brazilian population.

\section{MATERIAL AND METHODS}

\section{Subjects}

The local Research and Ethics Committee approved this study under protocol number 0132.314.000-09. Informed consent was obtained from all participating individuals or parents/legal guardians.

Two hundred eighteen (218) patients with cleft and in absence of any known cleft associated syndrome were recruited (mean age: 17.2 \pm 10.8 years old). None of the index cases were diagnosed with median cleft. Index cases were ascertained through the Hospital Municipal Nossa Senhora do Loreto (Reference Hospital for Oral Cleft Treatment), located in Rio de Janeiro, Brazil.

The determination of the cleft phenotype was based on the clinical examination. Cleft status was based on cleft laterality (left, right and bilateral) and cleft severity (comprised of primary and secondary palates entirely). Abbreviations for cleft type classifications were attributed as follows: CL - cleft lip; CP - cleft palate only; CLP - cleft lip and palate; $C L \pm P$ - cleft lip+cleft lip and palate excluding cleft palate only.

Tooth agenesis was considered when at least one developmentally missing permanent tooth was observed. This condition represents an important factor in the cleft subphenotypes determination. 
Only dental anomalies outside the cleft area were considered for CL and CLP. For the CP subjects, all dental anomalies observed were considered. Dental anomalies adjacent to the cleft area (affecting maxillary central incisors, lateral incisors, or canines) were not included in this study because the absence of such teeth may be the consequence of developmental anomalies at the cleft site ${ }^{19}$.

The control group $(n=253)$ was selected among patients and workers in School of Dentistry at Federal University of Rio de Janeiro (mean age: $20.4 \pm 16.4$ years old). Individuals were eligible as a control only if they had no congenital malformations, dental anomalies and family history of oral clefts.

All the evaluated subjects were recruited from July to December 2009. Epidemiological data such as ethnicity, family history of clefts and mother's habits during pregnancy including cigarette smoking and alcohol consumption were obtained by standardized questionnaires. The ethnicity definition was ascertained based on selfreported information. Both institutions where the subjects were recruited are located in the Rio de Janeiro state, in the Southeast of Brazil, one of the most densely populated and industrialized regions of the country. This region comprises an ethnic admixture of Caucasians (47.4\%) and African descent $(52.0 \%)$. The remaining $0.6 \%$ of the population is of Amerindian or Asian descent ${ }^{9}$.

\section{PCR-RFLP}

Genomic DNA for molecular analysis was extracted from cells detached of oral mucosa by mouthwash using SDS and proteinase $k$ digestion ${ }^{16}$. The purified DNA was used to determine the EGF $+61 \mathrm{~A}>\mathrm{G}$ polymorphism using the polymerase chain reaction - restriction fragment length polymorphism (PCRRFLP) technique as previously described ${ }^{29}$. The PCR reaction was carried out in $30 \mu \mathrm{L}$ mix containing 160 ng of genomic DNA, 1x Dream Taq Buffer (Fermentas, Maryland, USA), $0.2 \mathrm{mM}$ of dNTPs (Fermentas, Maryland, USA), $0.3 \mu \mathrm{M}$ of each primer (Forward: 5' TGTCACTAAAGGAAAGGAGG3'; Reverse: 5' TTCACAGAGTTTAACAGCCC 3' - Invitrogen, CA, USA) and $1 \cup$ Dream Taq DNA Polymerase (Fermentas, Maryland, USA). The cycling conditions comprised an initial denaturation step for $10 \mathrm{~min}$ at $96^{\circ} \mathrm{C}$, followed by 44 cycles consisting of three steps: $96^{\circ} \mathrm{C}$ for $30 \mathrm{~s}, 61^{\circ} \mathrm{C}$ for $30 \mathrm{~s}$ and $72^{\circ} \mathrm{C}$ for $1 \mathrm{~min}$. A final extension step was performed at $72^{\circ} \mathrm{C}$ for $10 \mathrm{~min}$. The fragment amplified (242bp) was digested with 2 $\mathrm{U}$ of Alu I (New England Biolabs, Maryland, USA) at $37^{\circ} \mathrm{C}$ overnight, electrophoresed on a $2.5 \%$ agarose gel stained with ethidium bromide and photographed under UV illumination. The digestion produced four fragments (15, 34, 91 and 102bp) when the A allele was present and three fragments (15, 34 and 193 $\mathrm{bp}$ ) in the presence of the $\mathrm{G}$ allele.

\section{Statistical analysis}

The data were processed and analyzed by using the GraphPad Instat (version 6.0) software. Odds ratio calculations and $\mathrm{X} 2$ or Fisher's exact tests at a level of significance of 0.05 were used to determine if any phenotype and subphenotype of oral cleft was preferentially associated with EGF genotypes and alleles. Moreover, the Hardy-Weinberg equilibrium was tested by the $\mathrm{x} 2$ test, comparing the observed versus the expected genotype frequencies.

\section{RESULTS}

The characteristics of the studied population are summarized in Table 1 . Out of the 471 individuals included in the study, 218 presented clefts and 253 did not (controls). In the cleft group, $87.6 \%$ had CL $\pm P$ (20.4\% of CL and $79.6 \%$ of CLP) and $12.4 \%$ had CP.

The occurrence of cleft was associated to maternal alcohol consumption during pregnancy $(p=0.04)$. The distribution of cleft type was statistically different according to gender with $\mathrm{CP}$ being more prevalent than CLP in females (Table 2). Considering the distribution of cleft type and laterality (bilateral or unilateral) or cleft severity (complete or incomplete) according to gender, no statistical differences were detected (data not shown).

Genotype distribution in cleft cases and controls was compared to evaluate the EGF+61 polymorphism association with clefts susceptibility. The banding patterns of PCR-RFLP EGF+61 A>G polymorphism are showed in Figure 1.

The polymorphism genotype distributions in cases and controls were shown in Table 3 and were consistent with those predicted from the HardyWeinberg equilibrium. The heterozygous AG was the most frequent genotype in both studied groups. The distributions of genotypes and alleles were similar, considering all cleft cases versus controls and $C L \pm P$ cases versus controls (Table 3 ). The same similarity was observed when all cleft cases and controls were stratified by ethnicity in Caucasian and African descents (blacks and mulattos) and compared $(p=0.063$ and $p=1.000$, respectively) (data not shown). The AA genotype frequency in CP patients was lower than in the control group, showing a borderline $p$ value $(p=0.054)$.

The frequency of the $A$ allele was higher in bilateral CL $\pm P$ patients $(54.6 \%)$, cleft cases with tooth agenesis (55.4\%) and cleft cases presenting family history of cleft (56.3\%) (data not shown) than in the control group, but no statistically significant differences were found. The AA genotype was over-represented in both bilateral $C L \pm P$ and patients with family history of cleft than in controls; the same pattern of genotype distribution was observed considering maternal smoking during pregnancy $(23.9 \%$ and $16.2 \%$ in cases and controls, 
respectively; data not shown) but we did not detect any statistical difference.

Comparing the different entities of nonsyndromic oral clefts ( $C L \pm P$ versus $C P$ ), we noticed that the allele $\mathrm{G}$ was most frequent in $\mathrm{CP}$ cases $(57.4 \%)$ compared with $C L \pm P$ cases $(47.4 \%$ ) (Table 3 ). This difference was statistically significant $(p=0.03)$.

\section{DISCUSSION}

To the best of our knowledge, we here present the first associative study assessing the EGF+61 $A>G$ polymorphism and nonsyndromic oral clefts risk. According to Shahbazi, et al. ${ }^{29}$ (2002), this variant may act as a functional polymorphism since

Table 1- Descriptive characteristics of cleft patients and controls

\begin{tabular}{|c|c|c|c|}
\hline \multicolumn{4}{|c|}{ Population characteristics } \\
\hline & Cleft & $\begin{array}{l}\text { Controls } \\
(n=253)\end{array}$ & $p^{*}$ \\
\hline \multicolumn{4}{|c|}{$(n=218)$} \\
\hline \multicolumn{4}{|l|}{ Gender, n (\%) } \\
\hline Female & $104(47.7)$ & $138(54.5)$ & 0.14 \\
\hline Male & $114(52.3)$ & $115(45.5)$ & \\
\hline \multicolumn{4}{|l|}{ Ethnicity, n (\%) } \\
\hline Caucasian & $128(58.7)$ & $153(60.5)$ & 0.70 \\
\hline African descent & $90(41.3)$ & $100(39.5)$ & \\
\hline \multicolumn{4}{|l|}{ Mother's habits during pregnancy, $\mathrm{n}(\%)$} \\
\hline Cigarette smoking & $46(21.1)$ & $37(14.6)$ & 0.07 \\
\hline Alcohol consumption & $26(11.9)$ & $16(6.3)$ & 0.04 \\
\hline \multicolumn{4}{|c|}{ Cleft group characteristics } \\
\hline & $\mathrm{CL}$ & CLP & CP \\
\hline & $(n=39)$ & $(n=152)$ & $(n=27)$ \\
\hline \multicolumn{4}{|l|}{ Cleft side, $\mathrm{n}(\%)$} \\
\hline Left & $24(61.6)$ & $70(46.1)$ & - \\
\hline Right & $10(25.6)$ & $33(21.7)$ & - \\
\hline Bilateral & $5(12.8)$ & $49(32.2)$ & - \\
\hline \multicolumn{4}{|l|}{ Severity of cleft, n (\%) } \\
\hline Complete & - & $148(97.4)$ & $22(81.5)$ \\
\hline Incomplete & - & $4(2.6)$ & $5(18.5)$ \\
\hline Associated tooth agenesis, $\mathrm{n}(\%)$ & $4(10.5)$ & $22(14.4)$ & $2(7.4)$ \\
\hline Positive cleft family history, n (\%) & $8(21.1)$ & $38(24.8)$ & $4(14.8)$ \\
\hline
\end{tabular}

${ }^{*}$ Fisher's exact test

CL: cleft lip; CLP: cleft lip and palate; CP: cleft palate only

Table 2- Distribution of cleft type according to gender

\begin{tabular}{ccccc}
\hline Cleft type & CL & CLP & CP & * $^{*}$ \\
\hline Gender & $(\mathbf{n = 3 9 )}$ & $(\mathbf{n = 1 5 2 )}$ & $(\mathbf{n = 2 7 )}$ & \\
\hline Males, $n(\%)$ & $16(41.0)$ & $89(58.6)$ & $9(33.3)$ & $\mathbf{0 . 0 2}$ \\
Females, $n(\%)$ & $23(59.0)$ & $63(41.4)$ & $18(66.7)$ & \\
\hline
\end{tabular}

${ }^{*}$ Chi-square test

CL versus CLP: $p=0.07$ (Fisher's exact test)

$C L$ versus $C P: p=0.61$ (Fisher's exact test)

CLP versus CP: $\boldsymbol{p}=\mathbf{0 . 0 2}$ (Fisher's exact test)

CL: cleft lip; CLP: cleft lip and palate; CP: cleft palate only 
AG AG AG AG AA AA AG AG GG

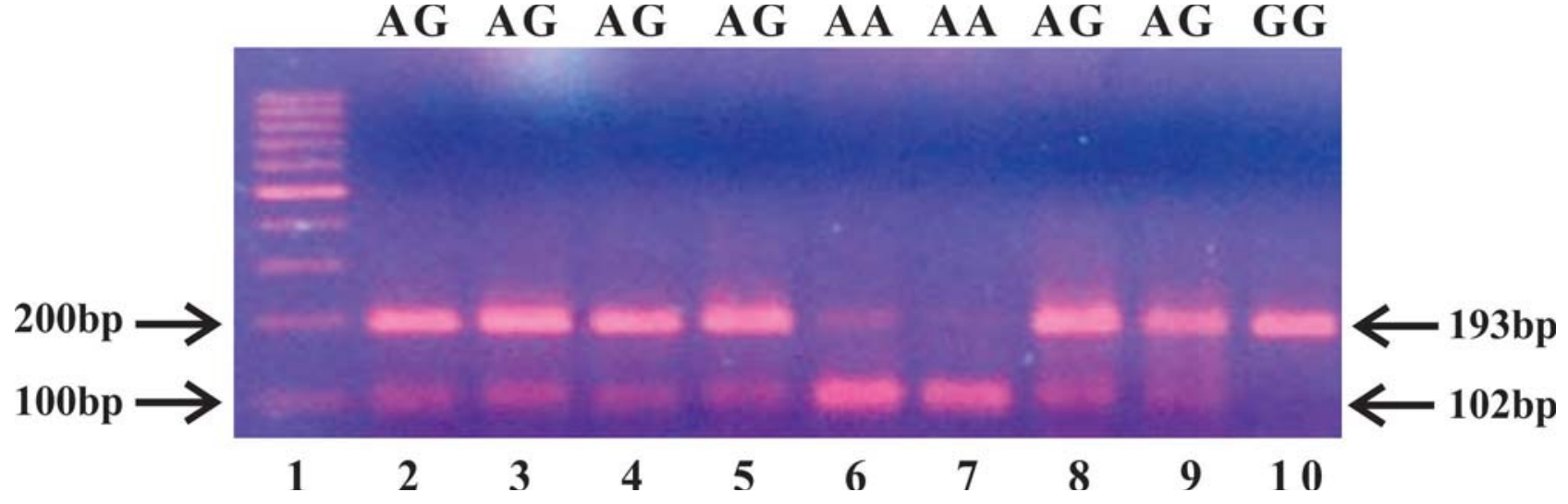

Figure 1- PCR-RFLP of EGF+61 $A>G$ polymorphism. Agarose gel electrophoresis of EGF DNA fragments stained with ethidium bromide. Lane 1:100bp DNA Ladder; Lanes 2-5, 8 and 9: heterozygous AG; Lanes 6 and 7: homozygous AA; Lane 10: homozygous GG. PCR-RFLP: polymerase chain reaction - restriction fragment length polymorphism; EGF: epidermal growth factor

Table 3- Association between EGF $+61 A>G$ polymorphism and clefts risk

\begin{tabular}{|c|c|c|c|c|c|c|c|c|c|}
\hline \multirow[t]{2}{*}{ Subjects } & \multirow[t]{2}{*}{$\mathbf{n}$} & \multicolumn{2}{|c|}{ Alleles n (\%) } & \multirow[t]{2}{*}{$\mathbf{p}^{*}$} & \multirow[t]{2}{*}{ OR $(95 \% \mathrm{Cl})$} & \multicolumn{3}{|c|}{ Genotypes n (\%) } & \multirow[t]{2}{*}{$p^{*}$} \\
\hline & & A & G & & & AA & AG & GG & \\
\hline Controls & 253 & $252(49.8)$ & $254(50.2)$ & - & Reference & $60(23.7)$ & $132(52.2)$ & $61(24.1)$ & \\
\hline All Clefts & 218 & $224(51.4)$ & $212(48.6)$ & 0.65 & $1.06(0.82-1.38)$ & $52(23.9)$ & $120(55.0)$ & $46(21.1)$ & 0.72 \\
\hline \multicolumn{10}{|l|}{ Cleft Type } \\
\hline$C L \pm P$ & 191 & $201(52.6)$ & $181(47.4)$ & 0.42 & $1.12(0.86-1.46)$ & $50(26.2)$ & $101(52.9)$ & $40(20.9)$ & 0.68 \\
\hline $\mathrm{CP}$ & 27 & $23(42.6)$ & $31(57.4)$ & 0.32 & $0.75(0.42-1.32)$ & $2(7.4)$ & $19(70.4)$ & $6(22.2)$ & 0.11 \\
\hline \multicolumn{10}{|l|}{$\begin{array}{c}\text { Cleft } \\
\text { Subphenotype }\end{array}$} \\
\hline Bilateral CL $\pm P$ & 54 & $59(54.6)$ & $49(45.4)$ & 0.40 & $0.82(0.54-1.25)$ & $16(29.6)$ & $27(50.0)$ & $11(20.4)$ & 0.63 \\
\hline Unilateral $C L \pm P$ & 137 & $142(51.8)$ & $132(48.2)$ & 0.60 & $0.92(0.69-1.24)$ & $34(24.8)$ & $74(54.0)$ & $29(21.2)$ & 0.80 \\
\hline Left CL $\pm P$ & 94 & $98(52.1)$ & $90(47.9)$ & 0.61 & $0.91(0.65-1.27)$ & $20(21.3)$ & $58(61.7)$ & $16(17.0)$ & 0.24 \\
\hline Right CL $\pm P$ & 43 & $44(51.2)$ & $42(48.8)$ & 0.91 & $0.93(0.60-1.50)$ & $14(32.6)$ & $16(37.2)$ & $13(30.2)$ & 0.19 \\
\hline $\begin{array}{l}\text { Cleft with tooth } \\
\text { agenesis }\end{array}$ & 28 & $31(55.4)$ & $25(44.6)$ & 0.48 & $1.25(0.72-2.18)$ & $8(28.6)$ & 15 (53.6) & $5(17.8)$ & 0.71 \\
\hline
\end{tabular}

${ }^{*}$ Fisher's exact test or chi-square test

EGF: epidermal growth factor; CL $\pm P$ : cleft lip+cleft lip and palate excluding cleft palate only; CP: cleft palate only

the base substitution can lead to changes in the EGF protein production. Moreover, the association of this polymorphism with clinical disorders including cancer has been described. Since cancer and oral clefts may share the same molecular pathways, the EGF+61 A>G polymorphism could be associated with nonsyndromic oral clefts risk.

The relationship between the $E G F+61 A>G$ polymorphism and cancer susceptibility is known, as well as the fact that risk allele vary between distinct ethnicities. The $G$ allele and GG genotype were associated with increased risk for gliomas in the European population and represent protective factors in the Chinese population ${ }^{12,32}$. Considering a Brazilian population from Rio de Janeiro, a high risk for gliomas was associated with the A allele and AA genotype ${ }^{31}$.

According to our results when evaluating nonsyndromic oral cleft patients, the A allele and AA genotype were over-represented in cleft cases compared to control group when we considered the bilateral $C L \pm P$ cases, cleft cases with tooth agenesis and cleft cases presenting family history of cleft. However, we did not observe a statistically significant difference. By interpreting these results, one limitation of our study could be the sample size that is still small and may not provide sufficient statistical power to estimate the association between EGF+61 A>G polymorphism and nonsyndromic oral cleft susceptibility in the population evaluated. 
Ardinger, et al. $^{5}$ (1989) also failed to confirm the association between two others EGF gene variations and nonsyndromic oral clefts.

The frequencies of several alleles vary significantly between populations, consistent with the possibility of false associations in case-control studies due to ethnic admixture. Any polymorphism found by chance at a higher frequency in a specific subgroup will appear to be associated with disease and will likely be a false positive. The Brazilian population is multiethnic, consisting mainly of people from European, African, and South Amerindian origin, being one of the most heterogeneous population in the world. Not surprisingly, our population presents large levels of genetic admixture. A study predicting the level of Brazilians African ancestry estimated by molecular biomarkers showed the Brazilian population presents African ancestry values intermediate between Europeans and Africans. Moreover, the southeast region of the country showed the most pronounced level of admixture. To prevent false-positive associations, the studied population in the present work was stratified in two different ethnic groups and the polymorphism frequencies were evaluated. The alleles' distribution were similar between whites (Caucasian) and non-whites (mulattos and blacks).

Genetic predisposition studies on human populations have demonstrated that $C L \pm P$ and $C P$ have distinct genetic backgrounds. In the present study, the EGF genotype distribution between $C L \pm P$ and $C P$ patients was statistically different being the $A A$ genotype over-represented in $C L \pm P$ cases and the GG genotype more common in CP cases. Genome Wide Association Studies (GWAS) have been identified several loci related with $C L \pm P$ susceptibility such as 1q32, 8q24, 10q25, 17q22, $2 p 21,13 q 31$, and $15 q 22^{22,23}$. However, the same relationship was not confirmed when $\mathrm{CP}$ cases were assessed ${ }^{23}$, suggesting that these clefting phenotypes have distinct etiologies and supporting the historical separation of $C L \pm P$ from $C P$.

Despite different research groups have performed notable attempts in the last decades to locate nonsyndromic clefts loci in the human genome, advances are still modest. The inheritance cannot be explained by a Mendellian simple model, displaying a very familial aggregation, which reveals the presence of an important genetic component. Mutations associated with genes of the EGF superfamily are implicated in malformations arising from abnormal development of the first branchial $a \mathrm{ch}^{5}$. Also, it was suggested the EGF as candidate gene to clefting since it plays a role in normal and abnormal palatogenesis in rodents ${ }^{1,13}$.

The possible interaction between EGF and other clefting-related genes in the same pathway, such as EGFR and TGFA (Transforming Growth Factor Alpha), may contribute to the nonsyndromic oral clefts susceptibility. It has been suggested that EGF, TGFA and EGFR play a role in cell proliferation and differentiation during primary palate morphogenesis which would then be relevant to clefting ${ }^{13}$. The teratogenic 2,3,7,8-tetrachlorodibenzo-p-dioxin (TCDD) exposure has been shown to disrupt EGF, EGFR and TGFA expression in the mice palate affecting the proliferation and differentiation of the medial epithelial cells resulting in cleft palate ${ }^{1}$.

Overall, TGFA as well as IRF6 are considered as genetic clefting modifiers in humans. However, mutations in TGFA gene were not associated with nonsyndromic cleft lip and palate in the Brazilian population ${ }^{6}$ and the role of IRF6 in our population is still unclear ${ }^{10}$. On the other hand, some variations such as polymorphisms in MMP3 and its inhibitor TIMP2 ${ }^{20}, \mathrm{BMP}^{2}$, and some markers discovered by GWAS, such as $1 p 36,15 q 22$ and $17 p 22^{4}$ showed significant associations with nonsyndromic oral clefts in recent studies with individuals from Brazil. A BMP4 polymorphism was also associated with upper lateral incisor agenesis considered a microform of $\mathrm{CL}$ in a Southeast Brazilian population ${ }^{3}$.

The association of a number of environmental factors and cleft risk has been reported, including maternal alcohol intake during pregnancy ${ }^{14}$. In the present study, we observed a relation between the increase of odds for $C L \pm P$ and $C P$ and maternal exposure to alcohol, in agreement with results obtained in a Brazilian case-control study ${ }^{17}$.

Another well-established environmental factor for cleft risk is maternal smoking during pregnancy ${ }^{14}$. Despite the high frequency of the AA genotype in cleft cases considering mother's cigarette smoking during pregnancy in the present study, maternal smoking was not associated with EGF $+61 \mathrm{~A}>\mathrm{G}$ polymorphism and the nonsyndromic oral clefts risk.

It has been proposed that tooth agenesis outside the cleft area could serve as marker for the definition of cleft subphenotypes ${ }^{19}$. So, we included tooth agenesis as a subgroup of oral cleft and observed that the $A$ allele was more frequent in the cleft cases with tooth agenesis compared with controls, with no statistical difference.

In summary, our data suggest that the EGF+61 $A>G$ polymorphism was not related with nonsyndromic oral cleft susceptibility in a population from the Southeast of Brazil. However, our results supported a different genetic background between CL $\pm P$ and CP. The potential effect of maternal alcohol intake on cleft risk was confirmed. Further larger sample-sized studies improving the statistical power and using high-throughput screening methods are needed to elucidate the role of this and others SNPs in candidate genes as contributors to nonsyndromic oral clefts risk. 


\section{ACKNOWLEDGMENTS}

The authors are indebted to the participants of the study and Hospital Municipal Nossa Senhora do Loreto, in Rio de Janeiro, Brazil. Support for this work was provided by the Coordination of Higher Education and Graduate Training (CAPES; fellowships for PFL, PNT and ECK), the Rio de Janeiro Research Foundation (FAPERJ; fellowship for JMG), the Brazilian Innovation Agency (FINEP; fellowship for JMG), the Science and Technology Department of the Ministry of Health (DECIT/MS; fellowship for JMG), and the National Council for Scientific and Technological Development (CNPq; fellowship for JMG).

\section{REFERENCES}

1- Abbott BD, Buckalew AR, Leffler KE. Effects of epidermal growth factor (EGF), transforming growth factor-alpha (TGFalpha), and 2,3,7,8-tetrachlorodibenzo-p-dioxin on fusion of embryonic palates in serum-free organ culture using wild-type, EGF knockout, and TGF alpha knockout mouse strains. Birth Defects Res A Clin Mol Teratol. 2005;73:447-54.

2- Antunes LS, Küchler EC, Tannure PN, Costa MC, Gouvêa CV, Olej $B$, et al. BMP4 polymorphism is associated with nonsyndromic oral cleft in Brazilian population. Cleft Palate Craniofac J. 2013;50:6338.

3- Antunes LS, Küchler EC, Tannure PN, Lotsch PF, Costa MC, Gouvêa CV, et al. TGFB3 and BMP4 polymorphism are associated with isolated tooth agenesis. Acta Odontol Scand. 2011;70:202-6. 4- Aquino SN, Messetti AC, Hoshi R, Borges A, Viena CS, Reis SR, et al. Analysis of susceptibility polymorphisms for nonsyndromic cleft lip with or without cleft palate in the Brazilian population. Birth Defects Res A Clin Mol Teratol. 2014;100:36-42.

5- Ardinger $\mathrm{HH}$, Buetow KH, Bell GI, Bardach J, VanDemark DR, Murray JC. Association of genetic variation of the transforming growth factor-alpha gene with cleft lip and palate. Am J Hum Genet. 1989;45:348-53.

6- Bertoja AE, Sampaio Alho C, De França E, Menegotto B, Miriam Robinson W. TGFA/TAQ I polymorphism in nonsyndromic cleft lip and palate patients from Rio Grande Do Sul, Brazil. Cleft Palate Craniofac J. 2008;45:539-44.

7- Bille C, Winther JF, Bautz A, Murray JC, Olsen J, Christensen K. Cancer risk in persons with oral cleft - a population-based study of 8,093 cases. Am J Epidemiol. 2005;161:1047-55.

8- Bjørge T, Cnattingius S, Lie RT, Tretli S, Engeland A. Cancer risk in children with birth defects and in their families: a population based cohort study of 5.2 million children from Norway and Sweden. Cancer Epidemiol Biomarkers Prev. 2008;17:500-6.

9- Brazilian Institute of Demography and Statistics (IBGE). 2010 Population Census. [cited 2015 Feb. 1]. Available from: http:// censo2010.ibge.gov.br/en/.

10- Brito LA, Paranaiba LM, Bassi CF, Masotti C, Malcher C, Schlesinger $D$, et al. Region $8 q 24$ is a susceptibility locus for nonsyndromic oral clefting in Brazil. Birth Defects Res A Clin Mol Teratol. 2012;94:464-8.

11- Cobourne MT. The complex genetics of cleft lip and palate. Eur J Orthod. 2004;26:7-16.

12- Costa BM, Ferreira P, Costa S, Canedo P, Oliveira P, Silva A, et al. Association between functional EGF+61 polymorphism and glioma risk. Clin Cancer Res. 2007;13:2621-6.

13- Iamaroon A, Wallon UM, Overall CM, Diewert VM. Expression of 72-kDa gelatinase (matrix metalloproteinase-2) in the developing mouse craniofacial complex. Arch Oral Biol. 1996;41:1109-19.
14- Kawalec A, Nelke K, Pawlas K, Gerber H. Risk factors involved in orofacial cleft predisposition - review. Open Med. 2015;10:163-75. 15- Kronmiller JE. Spatial distribution of epidermal growthfactor transcripts and effects of exogenous epidermal growth factor on the pattern of the mouse dental lamina. Arch Oral Biol. 1995;40:137-43.

16- Küchler EC, Tannure PN, Falagan-Lotsch P, Lopes TS, Granjeiro JM, Amorim LM. Buccal cells DNA extraction to obtain high quality human genomic DNA suitable for polymorphism genotyping by PCR-RFLP and Real-Time PCR. J Appl Oral Sci. 2012;20:467-71. 17- Leite IC, Koiffman S. Oral clefts, consanguinity, parental tobacco and alcohol use: a case-control study in Rio de Janeiro, Brazil. Braz Oral Res. 2009;23:31-7.

18- Leslie EJ, Marazita ML. Genetics of cleft lip and cleft palate. Am J Med Genet C Semin Med Genet. 2013;163C:246-58.

19- Letra A, Menezes R, Granjeiro JM, Vieira AR. Defining subphenotypes for oral clefts based on dental development. J Dent Res. 2007;86:986-91.

20- Letra A, Silva RM, Motta LG, Blanton SH, Hecht JT, Granjeiro JM, et al. Association of MMP3 and TIMP2 promoter polymorphisms with nonsyndromic oralclefts. Birth Defects Res A Clin Mol Teratol. 2012;94:540-8.

21- Li YL, Tian Z, Zhao L, Zhang CL. Association between the EGF rs4444903 polymorphism and liver cancer susceptibility: a metaanalysis and meta-regression. Genet Mol Res. 2014;13:8066-79. 22- Ludwig KU, Mangold E, Herms S, Nowak S, Reutter H, Paul A, et al. Genome-wide meta-analyses of nonsyndromic cleft lip with or without cleft palate identify six new risk loci. Nat Genet. 2012;44:968-71.

23- Mangold E, Ludwig KU, Birnbaum S, Baluardo C, Ferrian M, Herms S, et al. Genome-wide association study identifies two susceptibility loci for nonsyndromic cleft lip with or without cleft palate. Nat Genet. 2010;42:24-6.

24- Marazita ML, Lidral AC, Murray JC, Field LL, Maher BS, Goldstein McHenry T, et al. Genome scan, fine-mapping, and candidate gene analysis of non-syndromic cleft lip with or without cleft palate reveals phenotype-specific differences in linkage and association results. Hum Hered. 2009;1168:151-70.

25- Murray JC. Gene/environment causes of cleft lip and/or palate. Clin Genet. 2002;61:248-56.

26- Parra FC, Amado RC, Lambertucci JR, Rocha J, Antunes CM, Pena SD. Color and genomic ancestry in Brazilians. Proc Natl Acad Sci U S A. 2003;100:177-82.

27- Rodrigues K, Sena MF, Roncalli AG, Ferreira MA. Prevalence of orofacial clefts and social factors in Brazil. Braz Oral Res. 2009;23:38-42.

28- Schutte BC, Murray JC. The many faces and factors of orofacial clefts. Hum Mol Genet. 1999;8:1853-9.

29- Shahbazi M, Pravica V, Nasreen N, Fakhoury H, Fryer AA, Strange RC, et al. Association between functional polymorphism in EGF gene and malignant melanoma. Lancet. 2002;359:397-401. 30- Shum L, Sakakura Y, Bringas P Jr, Luo W, Snead ML, Mayo $M$, et al. EGF abrogation-induced fusilli-form dysmorphogenesis of Meckel's cartilage during embryonic mouse mandibular morphogenesis in vitro. Development. 1993;118:903-17.

31- Silveira FC, Lopes BA, Fonseca CO, Quirico-Santos T, Palmer Paixão IC, Amorim LM. Analysis of EGF $+61 A>G$ polymorphism and EGF serum levels in Brazilian glioma patients treated with perillyl alcohol-based therapy. J Cancer Res Clin Oncol. 2012;138:1347-54. 32- Tan D, Xu J, Li Y, Lai R. Association between $+61 \mathrm{G}$ polymorphism of the EGF gene and glioma risk in different ethnicities: a metaanalysis. Tohoku J Exp Med. 2010;222:229-35. 